\title{
"Selection of parameters for multifactor model in the knowledge economy marketing (country level)"
}

\author{
Maxim Polyakov iD https://orcid.org/0000-0001-7896-2486 \\ R http://www.researcherid.com/rid/V-9971-2018 \\ Vladimir Bilozubenko iD https://orcid.org/0000-0003-1269-7207 \\ AUTHORS \\ R http://www.researcherid.com/rid/V-9965-2018 \\ Maxim Korneyev iD https://orcid.org/0000-0002-4005-5335 \\ R http://www.researcherid.com/rid/B-7032-2018 \\ Gennadiy Shevchenko iD https://orcid.org/0000-0003-3984-9266 \\ R http://www.researcherid.com/rid/V-9077-2018
}

Maxim Polyakov, Vladimir Bilozubenko, Maxim Korneyev and Gennadiy Shevchenko (2019). Selection of parameters for multifactor model in the knowledge economy marketing (country level). Innovative Marketing , 15(1), 8999. doi:10.21511/im.15(1).2019.08

NUMBER OF REFERENCES

25
NUMBER OF FIGURES

0

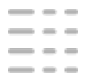

NUMBER OF TABLES

0

(C) The author(s) 2023. This publication is an open access article. 


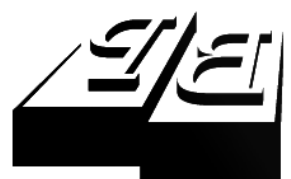

BUSINESS PERSPECTIVES

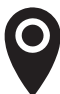

LLC "CPC "Business Perspectives" Hryhorii Skovoroda lane, 10, Sumy, 40022, Ukraine

www.businessperspectives.org

Received on: $12^{\text {th }}$ of February, 2019 Accepted on: $18^{\text {th }}$ of March, 2019

(c) Limited Liability Company "Consulting Publishing Company

"Business Perspectives", 2019

Maxim Polyakov, $\mathrm{PhD}$ in Economics, Managing Partner of Noosphere Ventures, Menlo Park, USA.

Vladimir Bilozubenko, Professor of the Department of International Economic Relations, Regional Studies and Tourism, University of Customs and Finance / D.Sc. (Economics), Associate Professor, Ukraine.

Maxim Korneyev, Professor of the Department of International Economic Relations, Regional Studies and Tourism, University of Customs and Finance / D.Sc. (Economics), Associate Professor, Ukraine.

Gennadiy Shevchenko, Candidate of Technical Science, Associate Professor, Association Noosphere, Ukraine.

Maxim Polyakov (USA), Vladimir Bilozubenko (Ukraine),

Maxim Korneyev (Ukraine), Gennadiy Shevchenko (Ukraine)

\title{
SELECTION OF PARAMETERS FOR MULTIFACTOR MODEL IN THE KNOWLEDGE ECONOMY MARKETING (COUNTRY LEVEL)
}

\begin{abstract}
Modern economy is characterized by rapid qualitative and quantitative changes that significantly affect the nature of economic, socio-economic and social relations. Innovative processes and trends are very specific manifestations, which are reflected in the economic and marketing theory. A greater place in science and practice is occupied by the concepts of new economy, knowledge economy, knowledge society. Therefore, the study of knowledge economy marketing becomes more and more relevant.

The paper is aimed to develop a technique for selection of the key parameters for building the model of national knowledge economy marketing.

For this purpose, it is proposed to conduct a cluster analysis based on aggregated data. Classification of differences between clusters is given. As a result of classification, the authors have identified a group of indicators, which make all clusters distinctive and, first and foremost, determine positions of countries in the global landscape. These indicators are interpreted as key factors of the knowledge economy.

Based on the suggested mathematical functions, the authors assessed the value of every key factor within the selected group. It became the second step in selecting the parameters to build a multifactor model of knowledge economy marketing at the national level. The paper also justifies that it is reasonable to use cognitive approach to address challenges in the sphere under consideration. This approach is able to become a sound basis for building the model of national knowledge economy marketing in the form of cognitive map.
\end{abstract}

\section{Keywords}

\section{JEL Classification I25, M31, M38}

\section{INTRODUCTION}

Theoretical and empirical analysis of the global economic development gives grounds for representing the knowledge economy as a new type of economic activity and higher level of development of national economies. Therefore, the concept of knowledge economy will become a basis for developing more sophisticated models of economic growth and improving economic systems at the next long cycle of development. This is the reason why the authors focus on building the knowledge economy, considering it not as a simple correction of proportions, but as an origination of a new economic paradigm, where the fundamental qualitative transformations will take place and new economic marketing principles will be implemented.

The changes at the national level will determine transformation of the whole world economy. Therefore, it becomes necessary to study a formation of knowledge economy at both national and global levels in close level-to-level relationship. The authors suggest considering the 
global landscape of knowledge economy formation as a reflection of the respective process in certain countries, as well as in the world economy. The study of the global landscape makes it possible to assess positions of individual countries and framework for marketing in an attempt to develop the knowledge economy.

Building of knowledge economy is a strategic goal of all countries, irrespectively from the level of their development, because it corresponds to the existing configuration of problems, accumulated in the previous cycle, as well as to objective requirements and trajectories of the human civilization evolution. However, a transition to the new type of economy will represent a long, complex and controversial process, requiring a governance from the outside. This governance can be exercised at different levels, including the national one, embracing the national economy as a whole. Government intervention (governance) is intended to compensate for the failures and risks of free market in the sphere of knowledge, at the same time harmonizing with the impact of market forces and guiding the economy in the right direction. For efficient state governance, it is required not only to have deep understanding of the specifics of knowledge economy and peculiarities of its formation, but also to use objective approaches, enabling to structure a vast number of factors (parameters) and being a basis for making decisions at the respective level.

An elaboration of such approaches requires respective theoretical and methodological background, in particular, for modelling. As knowledge economy is more complex (in terms of structure, institutes, processes, etc.) than the industrial economy, it becomes very difficult to create marketing models. Therefore, this paper is aimed to elaborate a technique for selection of the parameters, representing the key factors of knowledge economy, which are the basis for building the model of marketing such economy at the national level. Identification of the key factors, on the one hand, gives an insight into a global landscape of knowledge economy and, on the other hand, it is required by individual countries to address the challenges in improving (or maintaining) their positions, exercising the respective control of parameters and properly focusing on the limited resources.

\section{LITERATURE REVIEW}

The basis of this work are the principles of knowledge economy concept, which were laid down by Drucker (1969), Machlup (1962), Lundvall and Foray (1996) and others. Their studies demonstrated essential features of knowledge economy and represented it as a vector of evolution of human civilization. A retrospective of the 19th20th centuries, when the processes of economic development were very expressive, shows well how knowledge turned into a critical economic resource and became a major focus for the economists. It is proved by, for example, Nelson and Phelps (1966). A number of researches, devoted to the growing importance of knowledge, have increased exponentially, being influenced by science and technologies, as well as in the course of industrial revolutions. In the second half of the 20th century, several waves of development of knowledge economy concept were observed, and the beginning of the 21 st century has been marked by another boom in the context of progress of information and communication technologies (ICT). It is also confirmed by attention paid to this concept by management of companies, governments and international organizations. Thus, the knowledge economy concept is widely used by the OECD and the World Bank for elaborating the national development strategies.

To the date, the subject of knowledge economy is very important, because it is considered as an economic growth and competitiveness source in all sectors of the economy (Hadad, 2017). A well-founded skepticism about knowledge economy, demonstrated e.g. by Godin (2006) and Azam (2006), should also be taken into consideration. Such criticism is entirely appropriate due to certain weakness of knowledge economy concept and it highlights the need for improvement. Even today the knowledge economy development principles have considerably enriched the content of national development strategies, various interna- 
tional doctrines, scientific and experts' discussion. However, sometimes these ideas are used metaphorically and excessively. Being aware of not only weaknesses of knowledge economy concept, but also its effectiveness, there is a strong belief that further elaboration of this theoretical orientation and practical application of these provisions has a promising future. Therefore, a number of studies will be referred to providing an evidence of the above-stated facts.

Thus, Sundać and Fatur Krmpotić (2011) focused on identifying different factors of knowledge economy that have an impact on economic growth. Recognizing the absence of a single scenario of such economy building, the authors use KAM methodology of the World Bank as a tool for comparative study among 118 countries. The results of the analysis proved the importance of knowledge economy factors and variables for sustainable economic growth (Sundać \& Fatur Krmpotić, 2011).

Similar study was carried out by Paličková (2014), which also assessed the impact of knowledge economy on the development of countries and their economic growth. On the basis of regression analysis, a positive correlation was found between the indicators of knowledge economy and the level of economic development of countries. In this context, the author emphasized the importance of economic and institutional regime, education, $\mathrm{R} \& \mathrm{D}$, innovations and ICT, as well as investment in knowledge (i.e. in the above-mentioned spheres). At the same time, the analysis did not show unambiguous positive impact of knowledge economy on economic growth (Paličková, 2014).

Eliasson (2001) proves the growing impact of knowledge-based capital. Such capital fosters economic growth and expands on the global market in a wide range of intangible assets, encompassing R\&D, data, software and design skills. Knowledge becomes particularly important under competitive and volatile global economy. It determines the content of policy at the national level, and this policy acquires new variations and options (Eliasson, 2001).

In the modern sense, knowledge economy is inconceivable without ICT. The latter became a matter of systemic significance and it transforms many processes, branches of economy and so- cial lifestyle, and, as a new structural basis, it also transforms qualitative levels of these spheres. This is proved by Becla (2012) who demonstrates not only specific features of the society and knowledge-based economy, equated with knowledge economy, but also the pressing issues of information sector development.

In terms of economic marketing at the national level, the researches, appropriately positioning the concept of knowledge economy, are of particular interest. Thus, Melnikas (2012) considers knowledge economy as a background for development of the European Union (EU) as interstate association, at the same time determining strategic decisions on enhancing the efficiency of national economies. The author gives priority to the issues of building of EU clusters and its networks focused on facilitation of scientific and technological progress and promotion of technology. The study also justifies the importance of general contexts (including economic, social and technological development), created by globalization and technological internationalization and its impact on all aspects of economic progress of the countries, particularly on the high-tech sector. At the macrolevel, concerning the fields of further research, the author singled out the issues of science marketing, which is directly related to the knowledge economy and deals with its other components (Melnikas, 2012).

V. Burja and C. Burja (2013) studied drivers of knowledge economy in other countries - new EU members. There is a reason to say that the concept of knowledge economy and advancement of its components are of particular importance for the developing countries to modernize their economies and bring social progress in harmony with the new global trajectories. Consequently, efficient marketing of knowledge economy is even more topical problem for these countries. In their analysis of the state of knowledge economy, V. Burja and C. Burja (2013) embrace the groups of elements relating to spheres such as innovative system, education and ICT. The econometric assessments of twelve new EU member countries proved that the education system and R\&D sector had a positive effect on the economic growth.

Marginson (2010) emphasizes the increasing role of the higher education (along with R\&D) for the 
global knowledge economy. This role is manifold, and it is apparent at the level of nation and individual people, encouraging many positive transformations of a society and cultural diversity. The higher education is quite heavily involved in globalization processes and, as a result, undergoes considerable changes. Marginson proves that the higher education (as well as the whole education) is one of the most critical columns in the structure of knowledge economy, interacting with other components and determining the level of its development. From the copoint of knowledge economy, the global landscape of higher education is of interest, encompassing government policy and development strategy for universities and international organizations (Marginson, 2010). When considering the role of education in the developing countries, Weber (2011) emphasizes its growing importance in the face of global markets due to the growing importance of intellectual capital. Among other things, education becomes very important in diversifying economy and social transformations in the context of knowledge economy building (Weber, 2011).

Balcerzak (2016) demonstrated the importance of not just human capital, but its quality, which becomes a fundamental prerequisite for global competitiveness. The author's assessment of the quality of human capital in European countries (2001-2012) confirms the relevance of multicriteria analysis of knowledge economy components at macroeconomic level (Balcerzak, 2016). Balcerzak and Pietrzak (2016) use a similar category to assess the quality institutes for knowledge economy based on institutional economics framework. It is critical that the authors emphasize global projections of knowledge economy formation, making the issues of national governance in the global environment more important. The institutes (and, accordingly, management) are represented as one of the determinants of the capacity of any country to use the knowledge economy potential.

A collaborative study by Melnikas, Yakubavichus, and Willis (2013) is worth to make a picture of the global landscape of knowledge economy. The authors consider a wide range of issues relating to building of such economy in the new global environment. The authors present knowledge economy as a basis for modernizing and enhancing the international competitiveness of national economies, and also as a new field of internationalization processes (including international business). This proves the relevance of the current article position. It is also important that the innovative sector is represented as one of the key components of knowledge economy reflecting the economic results. In their work, Guzek and Kur (2018) demonstrated the connection of immigration and the principles of knowledge economy. In his book, Unger (2018) demonstrated that knowledge economy will become most advanced practice of production. It should radically change human life and the nature of economic activity. Dima, Begu, Vasilescu, and Maassen (2018) in their work discovered influence of different indicators of the knowledge economy on competitiveness of the country.

Lopez-Leyva and Mungaray-Moctezuma (2017) stress the growing closeness of the relationship between knowledge and economic development at the new stage, and, accordingly, present knowledge economy as a foundation for progress of different countries. The authors demonstrated strong points of diverse models: use of patents (Asian group), institutional system (Anglo-Saxon group), innovative capabilities and quality of higher education (European group) (Lopez-Leyva \& Mungaray-Moctezuma, 2017). It is also helpful in understanding the global landscape.

The analysis showed that the problems of knowledge economy development were studied quite fragmentarily. In particular, still there are no holistic approaches and models to control parameters of knowledge economy at the national level, required for its development. In this area, one can find just general idea of structuring knowledge economy parameters and subconscious comprehension of practices to control these parameters. As a result, subjectivism and heuristic approaches, and often scholasticism and trial-and-error approach dominate in this sector. This state of affairs does not enable to enhance the efficiency of knowledge economy development and creates a challenge while developing new marketing models, which are essential, primarily, in terms of practice.

Therefore, this study is aimed at developing fundamentals for building the multifactor model of 
knowledge economy marketing at the national level and at selecting the key parameters (informative group of features ${ }^{1}$ ) to build this model. It is expected to be achieved based on the previous research results, generalizing the indicators of different national knowledge economies, conducting cluster analysis and classifying the identified clusters.

\section{METHODOLOGY}

As an indirect confirmation of the recognition of the developed countries' economic transformation, a state called "knowledge economy", we can regard the appearance of the corresponding assessment tools and indicators.

In 2004, the World Bank has developed the strategic program "Knowledge for Development" (K4D), in which the future social and economic development paradigm was conceptualized, where the knowledge is the main factor and the resource. On the basis of this, the Knowledge Economy Index (KEI) was offered, which was being calculated until 2012 and had to enable to assess the ability of the countries to generate, distribute and use the knowledge (within the KEI, the consolidated Knowledge Economy Index was also being calculated, the indicators of separate countries and groups of countries were analyzed).

The KEI was based on the method "Knowledge Assessment Methodology" and was aimed at characterizing the knowledge economy development level across the countries at a global scale. The Index was represented as an integral indicator, which contained 109 structural and qualitative indicators, divided into 4 groups: 1) economic Incentive and institutional regime; 2) education and human resources (Educated and Skilled Workers); 3) innovation system (Effective Innovation System); 4) information and communication technology (modern and adequate information infrastructure). Such a format of the Index and its annual calculation had to become a reliable basis for the state management, allowing to determine the problem areas, changes, readiness to use the knowledge economy models. The parameters included in the KEI reflected the determination of the knowledge economy performance, including its institutional, economic, social and technological factors.

The key idea of the KAM is that the generation, distribution and use of knowledge are within the economic development process, which is viewed as knowledge economy (The World Bank, 2007). This circumstance points to the need for changing the theoretical and methodological constituents of marketing and development of its methods and instruments in practical terms. It is reasonable to talk about the emergence, scientific and practical development of knowledge economy marketing in the context of the transformations the world undergoes today. This requires new theoretical, methodological and methodical studies, which could have enabled to manage the key processes and knowledge economy development through the lens of marketing.

Taking into account the World Bank's concept and methodology, a cluster analysis was conducted, which divided 45 countries into clusters according to a wide range of parameters characterizing the knowledge economy components. These components and their relations serve as a structural and analytical model, representing the knowledge economy as a synergistic unity of components such as: education, science, ICT, high-tech production, and innovative business.

The clustering was conducted by various years. $k$-means algorithm was applied. The distance between the objects was chosen as a similarity criterion. Euclidean distance was taken as a metrics. As a result of cluster analysis, the countries (where a complete set of data was acquired) were divided into four clusters (by year).

Based on the clusters derived (deemed as classes of the objects under study) and using structural and logical methods, classification processing was conducted with the purpose to find distinctions between different classes (classification methodology is described by Polyakov, Shevchenko, \& Bilozubenko, 2018). Following the classification, among all indicators of the learning sample, those were selected where the values dramatically varied

1 Similar terms - factors, indicators, and parameters - are used very often. Therefore, it will be further considered that these terms have equal meaning in this paper. 
in the countries that belong to different clusters. It means that these indicators divide all clusters and are critical for identifying the position of every country. Therefore, they can be called key factors of knowledge economy, reflecting its development at the national level. For management purposes, it is essential to take into account that the values of these indicators, first of all, identify the position of one or another country in the global landscape and its belonging to a certain cluster. Accordingly, change of this group of indices will, primarily, ensure transition of countries from one cluster to another. Following the classification processing by every year, the groups of indicators were singled out representing the knowledge economy key factors. Using these indicators, the marginal values of parameters were identified by each cluster, which allowed for identifying the positions of individual countries.

The cauterization and classification results provide a clustering landscape of knowledge economy, as well as change of the key factors. However, it creates just basic guidelines for management by countries and narrow capabilities to synthesize new decisions. There is an opportunity to conduct additional parametric analysis of knowledge economy components in each country cluster (calculating, for instance, dispersion, median, statistical deviation, coefficient of skewness, etc.), although it will provide just general assessment and reference points.

\section{RESULTS}

The paper sets the objective to select parameters to develop multifactor model for knowledge economy marketing at the national level, summarizing empirical data of a large number of countries, representing the lion's share of knowledge generation and application, and determining the global trajectories of knowledge economy building. Considering the knowledge economy as inert-free system, the model should allow to manage somehow its parameters at the national level. Therefore, it is reasonable to classify this model as macroeconomic. It will have to reflect parameters (values), structure, processes and results and to enable generation of decisions at the national economy level.
Multifactority, arising from dependence on a huge variety of features, can be seen in each of the five basic columns of knowledge economy, and generally in knowledge economy as a single synergetic system. This poses challenges for structuring its parameters and makes selection of the key factors reasonable. At the same time, horizontal equality of all components of knowledge economy is taken into consideration regardless of their mutual impact. Equal significance of all parameters is also taken into account.

The term "global landscape" is used to define structural, resource and ordinal characteristics of the world economy, covering diverse groups of countries, in this case, as applied to knowledge economy. Realizing that it is necessary for countries to consolidate for advancement of knowledge, the structure and set of parameters of knowledge economy are understood universally, and the "world of knowledge" is considered as a single whole. As noted earlier, development of models to manage knowledge economy parameters is focused not only on situational assessment by countries, but also on research of changes in the global landscape of such economy, including a study of proportions of knowledge economy components, dynamics and positions of certain countries, transformation of their cluster composition. Given the context of formation of the global landscape and architecture of modern economic leadership, marketing of knowledge economy parameters at the national level is aimed at improving position of a country in the world economy.

The studies that have been carried out (cluster analysis and classification) enhance the insight into the global landscape of knowledge economy, as these studies allowed to identify factors, which, above all, structure this landscape, determine the dynamics and positions of individual countries. This improves the ability of comparative analysis and study of global trends in the development of knowledge economy and identifies the areas of observation studies (for example, assessment of the dynamics and synchronism of changes by countries and their groups).

This paper is based on the generally accepted understanding of management at the macrolevel. In particular, it is presented as a multisession process 
(with some degree of freedom, varied description of functions, ranges of parameters variation, etc.); it implies an impact on parameters to change them wholly and individually, pursuing the goals of economic development; it is characterized by the level of quality, which should be evaluated additionally; it is subject to certain constraints hindering achievement of parameters' optimal values (target function and indicators); among other things, it is based on identification of the determinants (in our case, the key factors), norms and criteria that is also a separate issue. A need for modelling arises out of the fact that the structured-by-components parameters (as a system of signs) bear a huge amount of information in contrast to individual parameters. This enables a search for a complex solution, more fully and precisely considering the relationship between variables (phenomena, processes). It also requires taking into account the information nature of every indicator (as a feature) and a system of indicators as a whole.

It is necessary to consider what kind of opportunities for management at the national level is provided by specific models (analytical, economic and mathematical). Above all, the models are the tool for analyzing empirical data to find new regularities, identifying determinants and optimal proportions. Models are also a language ("sign"), used to communicate the obtained results. The model, by its nature, represents a basis for understanding correlations, relationship and significance of different parameters, allowing us to understand what areas of knowledge economy we have to focus on. All this is translated into practice in the sphere of marketing and serves as a reliable foundation for decision-making: in setting goals, planning, marketing and regulation. It is assumed that the outcomes of this study will be useful for further theoretical research, defining scientific objectives and research hypotheses. An application of models often provides an opportunity to identify new objects of research and outline their structure (analytical frames).

As it was mentioned above, a necessity to use multifactor models for marketing arises from multiplicity of knowledge economy components, a large number of input and resultant parameters. The applicability of the models arises from clarity of decisions, which can be justified based on such models, and from the opportunity to consider different combinations of parameters, versions and ranges in obtaining target indicators that is critical, because the truth can be only seen from different perspectives. Most often, while marketing complex systems, we have to face their variability, lack of a single correct value of the indicator, "corridors" of decisions, changing and stochastic nature of cause-effect relationship (dependencies, subordination, interactions) between the indicators at system level. Therefore, we also have to identify the key factors and to understand their correlation. This requires specific approaches and $\operatorname{cog}$ nitive vision. Modern approaches, using different mathematical methods (correlation, regression and multifactor analysis) and being mainly devoted to identification of "rigid" link and dependence between parameters, do not always yield the expected results. This draws attention to cognitive modeling.

Given the quality of the available official statistics, the above-stated data sampling is sufficient and relevant for macroeconomic modelling. The parameters of the sampling are interrelated, but it is impossible to assume the nature of their interrelationship (dependency), as well as a number of model building versions at the initial stage. Official statistics on this data is prepared on systematic basis. The sampling summarizes both quantitative and qualitative (e.g., ordinal) variables. The parameters are heterogeneous and specific, and they explain diverse components of knowledge economy. There are no mutually exclusive parameters. It is believed it is necessary to retain ordinal ratings and indices, even being aware that initial data affect them.

The sample of indices makes an analytical foundation for modelling. This summarized set of data represents a numeric system, which, as can be seen, cannot fully reflect an empirical (real) subject area. However, it should be assumed that, at the beginning, this set of data reflects significant characteristics of knowledge economy, and the results of classification processing actualize its most critical factors and, consequently, can serve as a foundation for development of the economic and mathematical model. An analysis demonstrates that almost all features of the learning sample as 
well as the major indicators (key factors), identified as a result of its processing, are more or less controllable.

Given a set of data and a limited group of key factors, it should be noted that there are almost no indicators, which can be sufficient or minimum required. Input and resultant indicators are subject to the imperative building-up (maximization), taking the effectiveness criteria into account. Ratings, indices and assessments, which have the upper limit but should seek to increase, are of particular significance.

\subsection{Analytical justification}

The process of marketing should have a clear objective. In terms of countries, the objective is set in the following way: to transit to a more successful country cluster in the shortest possible time (the cluster of countries with higher level of knowledge economy development). This also applies to the countries of the first cluster, as it is critical for them to maintain the leading positions, correcting the lag in certain indicators.

The paper shows that there are a lot of parameters to influence and increase. When resources are limited, the factors (indices) to focus on and to strengthen efforts (if possible, without limiting other indicators) should be selected in order to improve the country position in the global landscape.

The classification made it possible to identify a group of key factors to focus on for marketing purposes. These factors are understood as structural "actants" of knowledge economy, where their increase will be the most successful to improve positions of a country. A specific numerical system of knowledge economy measurements is being established at both national and global levels. However, the set of key factors also comprises a few parameters, which have to be prioritized while evaluating their relevance to address the objective set.

\subsection{Mathematical justification and results}

Acting consistently from clustering to classification, the key factors of knowledge economy were identified according to different years. The obtained sets of indicators are considered as the information groups of features (IGF). While proceeding to modelling, a new function has to be introduced that will allow us to evaluate contribution of each key factor to the IGF in each of the years. This will make it possible to prioritize every key factor and will provide a capacity to control more effectively, concentrating resources and efforts.

The following formula is suggested to determine key factors, such as IGF:

$$
V\left(x_{i_{1}}, \ldots, x_{i_{j}}\right)=\frac{1}{k} \sum_{\Delta \in \Gamma} \max _{Y}\left(\frac{m_{\Delta Y}}{m_{Y}}\right),
$$

where $k$ - a number of classes (clusters) in the learning same, $m_{Y}$ - a number of objects, belonging to a class (cluster) $Y, \Delta=t_{i_{1}}, t_{i_{2}}, \ldots, t_{i_{j}}$ $\left(0 \leq t_{i_{j}} \leq k_{i_{j}}-1\right), \quad j=1, \ldots, \gamma-$ an arbitrary set of factor values $x_{i_{1}}, \ldots, x_{i_{1}}(1 \leq \gamma \leq n), m_{\Delta Y}-\mathrm{a}$ number of sampling sets from $m$ class of the learning sample that the following correlation is performed: $x_{i_{j}}=t_{i_{j}}(j=1, \ldots, \gamma), t_{i_{j}}$ - value of factors (features) $x_{i_{j}}$ in the set $\Delta, \Gamma$ - a multitude of all sets of factors (features) $x_{i_{1}}, \ldots, x_{i_{j}}$.

In case of the full distinguishability of the classes, this evaluation takes limit value equal to 1 . It is important to note that such value is calculated directly from the data of the learning sample and characterizes distinguishing ability of the latter.

Taking into account the objective set and an aspiration to ensure the effective management with the limited resources, it is required to single out from the IGF the factors, which mostly influence the state of the object, i.e. belonging of a country to one or another cluster (thereby to prioritize these factors). In fact, it means that we are interested in a contribution of certain factors to the above-stated formula (1), which enables more profound understanding of these factors in terms of marketing. This evaluation is useful as a criterion for selection of the change parameters, which would be the most resultant to change the country position.

The following new function is suggested to evaluate the impact of IGF factors on overall evaluation (formula 1): 


$$
\begin{aligned}
& W\left(x_{i_{j}}\right)=1-V\left(x_{i_{1}}, \ldots, x_{i_{j-1}}, x_{i_{j+1}}, x_{i_{s}}\right), \\
& 1 \leq s \leq n .
\end{aligned}
$$

As previously mentioned,

$$
V\left(x_{i_{1}}, \ldots, x_{i_{j-1}}, x_{i_{j+1}}, x_{i_{s}}\right) \leq 1 \text {, then } W\left(x_{i_{j}}\right)
$$

will always be of a positive value, less than 1 .

Using the formula (2), it becomes possible to evaluate a contribution of every factor to the summary component of information value of the initial set of factors included in IGF, thereby getting a chance to evaluate their distinguishing ability in this respect.

For example, based on the classification and formula (1) on the latest cross-section of empirical data, the following key factors of knowledge economy (like IGF) were singled out (from the variety represented by (Polyakov, Shevchenko, \& Bilozubenko, 2018): 1) gross enrolment ratio, tertiary $\left(x_{2}\right)$; 2) mean years of schooling $\left(x_{5}\right)$; 3) patent grants, residents $\left(x_{11}\right)$; 4) networked readiness index $\left(x_{14}\right)$; 5) technological readiness $\left(x_{18}\right)$. Using the formula (2) for processing of this IGF data, the following sequence was obtained:

$W\left(x_{2}\right)=0.08, W\left(x_{5}\right)=0.07, W\left(x_{11}\right)=0.16$, $W\left(x_{14}\right)=0.06, W\left(x_{18}\right)=0.03$.

It is evident that the major contribution to IGF is made by factor $x_{11}$ "Patent grants, residents", then by the following factors: $x_{2}$ "Gross enrolment ratio, tertiary", $x_{5}$ "Mean years of schooling", $x_{14}$ "Networked Readiness Index", $x_{18}$ "Technological readiness".

Therefore, the suggested approach allowed the authors to not only classify and identify the factors of information group of features, but also to evaluate contribution of each of the factors to information value of this group. In future, it will enable to develop practical measures to be taken first in order to transit to the cluster of more successful countries as soon as possible (or to maintain the leading positions). In other words, marketing will rely not only on the total set of data, but also on the group of key factors, taking into consideration their significance, and distributing resources and efforts more efficiently. Thus, as far as the greatest contribution to distinguishability of clusters is made by factor $x_{11}$, then the management, aimed at transition to the higher cluster, should begin from this factor and thereafter, one by one (successively, according to the contribution) involve other factors of the information group of features in the process of marketing.

However, to exercise marketing, an appropriate model is needed linking the key factors. At the same time, to address the objectives in the described area, it is almost impossible to create traditional formal quantitative models. Here, most likely, one needs experience, intuition, guesses and associations. The objectives of such type are called cognitive and are addressed by a special science - knowledge engineering.

After preliminary analysis (clustering and classification), a set of key factors, having the most impact on the condition of knowledge economy in a group of countries under consideration, was determined and broken down by clusters (verified as classes). Using a cognitive approach as the most appropriate tool to study such kind of systems, it is necessary at first to identify the relationship between the factors and indicate their links with the world around. Such description can be visually depicted in the form of column, table, text, etc. Most often, and for illustrative purposes, such description is represented as a column or so called cognitive map, i.e. actually the structural cause and effect diagram is built, as it allows to better understand and analyze behavior of the complex system.

An approach to addressing the objective of finding the key factors of knowledge economy was suggested. Also, distinctions between country clusters are described, and an approach to evaluating their contribution to IGF for marketing purposes is proposed in order that these countries could efficiently improve their positions and transit into the higher cluster (if remaining within the introduced formalization and following the formulated marketing objective). As the result, the analytically and empirically justified foundation for developing a cognitive map in future was obtained.

A detailed description of the process of cognitive map development and marketing method- 
ology on its basis is beyond the scope of this article and will be presented in further publications. New research will be devoted to developing a general cognitive map, reflecting and formalizing a mechanism of "knowledge economy" system, analyzing its properties and devel- oping general methodology of marketing. The next stage will be a building a cognitive map based on the obtained structure, "unveiling" its apexes and explaining their subordination, and modeling the dynamics of processes in numerical data.

\section{CONCLUSION AND ADDITIONAL OBJECTIVES}

A group of key factors of knowledge economy was determined based on the previous studies (clustering of countries and classification). This enhances the insight into the global landscape of such kind of economy, namely, into the factors, which structure it and determine positions of individual countries.

The identification of the key factors makes marketing more efficient and focusing the resources and having an impact on these factors improves position of a country in the global landscape (to transit to the cluster of more successful countries or to maintain the leading positions). It became the first step in selecting the parameters to build the multifactor model of national knowledge economy marketing. The second step, implemented in this paper, was an elaboration of new mathematical functions (formulae 1 and 2) and assessing on their basis the significance of every factor in the group of the key ones, which makes it possible to specify the model for more efficient marketing.

It is rational to use cognitive approach to address the marketing objectives in the sphere under consideration. Within this framework, the multifactor model of knowledge economy marketing can be constructed in the form of cognitive map of parameters, selected based on mathematical functions suggested in this paper. This is expected to be implemented in further research.

\section{REFERENCES}

1. Azam, G. (2006). L'utopie de l'economie de la connaissance. Problèmes économiques, 2901, 33-39.

2. Balcerzak, A. (2016). Multiplecriteria Evaluation of Quality of Human Capital in the European Union Countries. Economics and Sociology, 9(2), 11-26. Retrieved from https://www. economics-sociology.eu/?398,en_ multiple-criteria-evaluation-ofquality-of-human-capital-in-theeuropean-union-countries

3. Balcerzak, A., \& Pietrzak, M. (2016). Quality of Institutions for Knowledge based Economy within New Institutional Economics Framework. Multiple Criteria Decision Analysis for European Countries in the Years 2000-2013. Economics and Sociology, 9(4), 66-81. Retrieved from https:// www.economics-sociology. eu/?445,en_quality-of-institu- tions-for-knowledge-based-economy-within-new-institutionaleconomics-framework.-multiplecriteria-decision-analysis-foreuropean-countries-in-the-years2000\%E2\%80\%932013

4. Becla, A. (2012). Information Society and Knowledge-based Economy - Development Level and the Main Barriers - some Remarks. Economics \& Sociology, 5(1), 125-132. Retrieved from https://economics-sociology.eu/ files/Agnieszka\%20Becla $\% 20$ V5N1.pdf

5. Burja, V., \& Burja, C. (2013). Drivers of knowledge economy in the EU's developing countries. $A n$ nals of the "Constantin Brâncuşi" University of Târgu Jiu. Economy Series, 2, 10-15. Retrieved from http://www.utgjiu.ro/revista/ ec/pdf/2013-02/2_Burja\%20 Vasile,\%20Burja\%20Camelia.pdf
6. Dima, A. M., Begu, L., Vasilescu, M. D., \& Maassen, M. A. (2018). The Relationship between the Knowledge Economy and Global Competitiveness in the European Union. Sustainability, 10(6), 1706. https://doi.org/10.3390/ su10061706

7. Drucker, P. F. (1969). The Age of Discontinuity: Guidelines to Our Changing Society. New York: Harper and Row.

8. Eliasson, G. (2001). The Role of Knowledge in Economic Growth. Research and knowledge management, 1-34. Retrieved from http:// www.oecd.org/innovation/research/1825633.pdf (accessed on October 10, 2018).

9. Godin, B. (2006). The KnowledgeBased Economy: Conceptual Framework or Buzzword? The Journal of Technology Transfer, 
31, 17-30. Retrieved from https:// link.springer.com/article/10.1007/ s10961-005-5010-x

10. Guzek, M., \& Kur, J. (2018). Knowledge Economy and the Immigration Policy. In Theory and Applications in the Knowledge Economy Conference from 11 to 13 July 2018 (pp. 62-63.). Poznan University of Economics and Business.

11. Hadad, S. (2017). Knowledge Economy: Characteristics and $\mathrm{Di}$ mensions. Management Dynamics in the Knowledge Economy, 5(2), 203-225. https://doi.org/10.25019/ MDKE/5.2.03

12. Lopez-Leyva, S., \& Mungaray-Moctezuma, A. (2017) Knowledge-Based Economy as a Foundation for the Economic Development of Countries. Management Dynamics in the Knowledge Economy, 5(4), 481-501. Retrieved from http://www.managementdynamics.ro/index.php/journal/ article/view/217

13. Lundvall, B.-A., \& Foray, D. (1996). The knowledge-based economy: from the economics of knowledge to the learning economy. Paris: OECD.

14. Machlup, F. (1962). The Production and Distribution of Knowledge in the United States. Princeton: Princeton University Press.

15. Marginson, S. (2010). Higher Education in the Global Knowledge Economy. Procedia - Social and
Behavioral Sciences, 2(5), 69626980. https://doi.org/10.1016/j. sbspro.2010.05.049

16. Melnikas, B. (2012). Knowledge economy in the European Union: Strategic decisions in the context of globalization. Challenges of the global economy. Working Papers of Institute of International Business University of Gdañsk, 31, 243-262. Retrieved from https:// ekonom.ug.edu.pl/web/download. php? OpenFile $=968$

17. Melnikas, B., Yakubavichyus, A., \& Vilis, M. (2013). Экономика знаний: интернационализация и систематика инноваций [Ekonomika znaniy: internatsionalizatsiya i sistematika innovatsiy]. Vilnyus: Litovskiy innovatsionnyy tsentr.

18. Nelson, R., \& Phelps, E. (1966). Investment in humans, technological diffusion, and economic growth. American Economic Review, 56(2), 69-75. Retrieved from https:// www.jstor.org/stable/pdf/1821269. pdf?seq=1\#page_scan_tab_contents

19. Paličková, I. (2014). Influence of the knowledge economy on the economic growth and economic level of the countries. Acta Academica Karviniensia, 2014(3), 139-147. Retrieved from http:// aak.cms.opf.slu.cz/pdf/2014/3/ Palickova.pdf (accessed on October 10, 2018).

20. Polyakov, M. V., Shevchenko, G. Y., \& Bilozubenko, V. S. (2018).
Clustering of countries in global landscape of knowledge economy development. Scientific bulletin of Polissia, 1(13), 176-183.

21. Sundać, D., \& Fatur Krmpotić, I. (2011). Knowledge Economy Factors and the Development of Knowledge-based Economy. Croatian Economic Survey, 13(1), 105-141. Retrieved from https://www.researchgate.net/ publication/227441408_Knowledge_Economy_Factors_and_ the_Development_of_Knowledge-based_Economy

22. The International Bank for Reconstruction and Development, The World Bank (2007). Building Knowledge Economies: Advanced Strategies for Development (212 p.).

23. Unger, R. M. (2018). The Knowledge Economy. OECD. Retrieved from https://www.oecd.org/naec/ THE-KNOWLEDGE-ECONOMY.pdf

24. Weber, A. (2011). The role of education in knowledge economies in developing countries. Procedia - Social and Behavioral Sciences, 15, 2589-2594. https://doi. org/10.1016/j.sbspro.2011.04.151

25. World Bank (n.d.). Building knowledge economies. Retrieved from https://openknowledge. worldbank.org/bitstream/handl e/10986/6853/411720PAPER0K n101OFFICIAL0USE0ONLY1. pdf? sequence $=1$ \&isAllowed $=y$ 